\title{
Self-Reported Basic Oral Health Knowledge of Primary School Students and Teachers in Rural Areas of Saudi Arabia
}

\author{
Rakan Shaheen' \\ Mohammed AIShulayyil ${ }^{2}$ \\ Mohammad Abdul Baseer (D) \\ Ahmed Abdullah Saeed Bahamid \\ Abdulrahman Dahham AISaffan' \\ Reem Al Herbisch ${ }^{3}$ \\ 'Department of Preventive Dentistry, \\ College of Dentistry, Riyadh Elm \\ University, Riyadh, Saudi Arabia; ${ }^{2}$ Ministry \\ of Health Hospital, Wadi Ad-Dawasir, \\ Saudi Arabia; ${ }^{3}$ College of Dentistry, \\ Riyadh Elm University, Riyadh, Saudi \\ Arabia
}

Background: Oral health knowledge is essential for establishing healthy behaviors.

Aim: The purpose of the study was to determine and compare the basic oral health knowledge of 3-6th grade government primary school students and teachers in rural areas of Saudi Arabia. Methods: A cross-sectional study was conducted among government primary school students and teachers in a rural area (Thadig and Ad-Delam) of the Riyadh region of Saudi Arabia using validated, structured, close-ended and self-administered questionnaires. The questionnaire comprised demographic variables and 18 multiple-choice items. A convenience sampling methodology was employed to select the study sample.

Results: A total of 1864 subjects from rural area government primary schools [students $(\mathrm{N}=$ $1538)$ and teachers $(\mathrm{N}=326)$ ] participated in this study. The majority of the students were females 841 (54.7\%), Saudi nationals 1376 (89.5\%), and studying in 5th grade 446 (29\%). Most teacher participants were females, 199 (61.0\%), and Saudi nationals, 326 (100.0\%). Teachers (12.62 \pm 2.36$)$ demonstrated significantly higher overall mean knowledge scores compared to the students $(9.63 \pm 2.36)(\mathrm{p}<0.001)$. Females and non-Saudi students showed significantly higher mean knowledge scores compared to their counterparts. However, 4th standard students showed significantly lower mean knowledge scores compared to other graders. Female teachers $(13.17 \pm 2.25)$ demonstrated significantly higher overall oral health knowledge scores compared to male teachers $(11.75 \pm 2.26)(\mathrm{p}<0.001)$.

Conclusion: Basic oral health knowledge was adequate among 3-6th grade government primary school students and teachers in rural areas of the Riyadh region.

Keywords: oral health, knowledge, rural, students, teachers

\section{Introduction}

Tooth decay and gum disease are the two most common oral health problems affecting children globally. ${ }^{1}$ According to recent statistics, the incidence of dental caries among Saudi schoolchildren is exceptionally high compared to industrialized and developing nations in the Eastern Mediterranean region. ${ }^{2}$ These oral health issues may cause pain, speech impairment, sleep disruption, problematic eating, and developmental difficulties, ${ }^{3}$ all of which have a negative impact on school attendance, performance, and future success. ${ }^{4}$ Because children are the nation's future, their health and well-being should be prioritized. ${ }^{3}$

Oral health literacy refers to the "degree to which individuals can obtain, process and understand basic oral health information and services needed to make appropriate health decisions". ${ }^{5}$ Oral health literacy is a thriving field. ${ }^{6}$ It has been
Correspondence: Mohammad Abdul Baseer

Department of Preventive Dentistry, College of Dentistry, Riyadh Elm University, Namuthajiya Campus, Pos Box No. 8489I, Riyadh, II68I, Saudi Arabia

Email ma_baseer@riyadh.edu.sa 
demonstrated that poor oral health literacy is linked to poor periodontal health, lack of utilization of preventive or therapeutic measures, and a lack of understanding of oral healthcare providers' messages. ${ }^{7}$ Oral and dental illnesses may be prevented, diagnosed, and treated more effectively if health literacy is sufficient. ${ }^{8}$ Moreover, oral and dental health literacy has been linked to substantial economic repercussions. ${ }^{9}$

Oral health knowledge is necessary for establishing healthy behaviors, and studies have demonstrated a link between improved knowledge and better oral health. ${ }^{10,11}$ Individuals are more likely to adopt optimal health practices if they feel more in control of their health due to increased understanding of diseases and their causes. ${ }^{12}$ According to the Integrated Theory of Health Behavior Change (ITHBC), health behavior may be improved by increasing knowledge and beliefs, strengthening selfregulation abilities, and improving social facilitation. ${ }^{13}$

Several studies have documented oral health knowledge attitudes and practices among school children and teachers in Saudi Arabia with variable findings. ${ }^{14-18}$ Study conducted in Abha, Saudi Arabia, revealed that most children did not brush and floss their teeth daily. While just more than half of the students were aware of the sweet as the cause of dental caries, and less than half related toothache to dental caries. Almost $82.3 \%$ were aware that good oral health is essential for general health; thereby, school students demonstrated fair oral health knowledge, suggesting a need for improved oral health knowledge. ${ }^{16,18}$ On the other hand, a study conducted among schoolteachers in various cities reported fair knowledge and a positive attitude toward oral health. ${ }^{14,17}$ Hence there is a need to address the existing oral health knowledge gap.

Despite many studies conducted on oral health knowledge of school students in Saudi Arabia, most studies were focused on the capital and major urban cities. However, there is a lack of data on the oral health knowledge of school children and teachers in rural areas of Saudi Arabia. Therefore, the study findings help to identify the gaps in students' and teachers' basic oral health knowledge in the rural settings of Saudi Arabia. Based on the identified knowledge gaps, tailored educational programs can be developed targeting rural schools to improve oral health literacy and behavioral changes conducive to good oral health and better lifestyles. Hence the present study aimed to determine and compare the basic oral health knowledge of 3-6th grade government primary school students and teachers in rural areas of Saudi Arabia.

\section{Study Subjects and Method Study Design and Setting}

This cross-sectional study was undertaken after obtaining formal approval from the research center of Riyadh Elm University (Registration Number: FRP/2018/271), Riyadh, Saudi Arabia. Two areas (Thadig and Ad-Delam) of the Riyadh region were listed for the study purpose. All the government primary schools in Thadig (Males 11 and Females 6) Ad Delam (Males 6 and Females 12) were considered in the study based on ease and access. Convenience sampling was employed to select the study participants.

Due to the gender-separated schooling at all levels in Saudi Arabia, male investigators were not allowed to enter the female campuses. Therefore, the help of the female teaching staff was sought during the study. Dental interns under the supervision of the two faculty members from the department of preventive dentistry visited 17 male and 18 female government primary schools in Thadig and Ad Delam area. Only governmental schools were preferred due to their predominance in these areas with of lack of access to dental care programs. Before the study began, the formal approvals of the local school authorities were obtained after describing the goals of the investigation. Data collection was performed during the first and second terms of schools - 2019. The parent or legal guardian of the students provided informed consent and that this study was conducted in accordance with the Declaration of Helsinki. Additionally, The purpose of the study was described to the students, and their assent was acquired.

\section{Study Sample}

This study included 3rd to 6th (aged between 8-11 years) grade male and female students from government schools. Sample size estimation was based on the alpha error probability $=0.05$, power $=0.90$, and effect size $=0.20$ with the teachers to student ratio of 0.21 . The sample size of 1538 students and 326 teachers was considered. Each class consisted of approximately 50-60 school students. A group of dental interns collected data from 3rd (335), 4th (353), 5th (446), and 6th (404) standard primary school children. The children who were absent during the data collection phase were excluded from the study.

\section{Study Instrument Development and Validation}

The English version of the questionnaire utilized in the previous study was translated into native Arabic using the 
forward and backward translation method. ${ }^{19}$ The questionnaire was pilot tested with a sample of forty students and ten teachers to ensure that it was brief and straightforward. In addition, the questionnaire was field-tested to determine its ease of use and accuracy in knowledge items. Cronbach's alpha of $85 \%$ was obtained, indicating adequate reliability.

\section{Questionnaire Contents}

The questionnaire was made up of 18 multiple choice questions with a single correct answer to each question. The questionnaire items included demographic information (age, gender, nationality, and educational level), followed by questions on structure, functions, and types of the teeth, food and tooth decay, toothbrushing-related information, oral and general health relation, and Loss of teeth and orthodontic treatment. The oral health knowledge of the students and teachers was assessed using a structured, self-administered, and close-ended printed questionnaire. Items like Doe's soft drinks affect teeth adversely? Does the health of mouth and dentition impact the health of the body? Loss of teeth can interfere with speech? Is it possible to move irregularly placed teeth into the correct position? Included responses such as yes, no, and I do not know (Supplementary Figures 1 and 2). Students and teachers took 5-7 minutes to respond to all the items.

\section{Assessment of the Oral Health Knowledge}

All the multiple-choice questions had a single best response. Every correct answer in the questionnaire received a score of one, while every incorrect response received a score of zero. The individual scores for each question were then added to produce an overall knowledge score. The overall knowledge score ranged between $0-18$, with a maximum score of 18 and a minimum of 0 . The overall score was categorized as poor, average, or high based on the number of correct responses. The poor category had an overall score of 9 or less, the average category had 9.1-14, and the high category had 14.1-18.

\section{Statistical Analysis}

Skewness and Kurtosis and visual inspection of the histograms showed the near-normal distribution of students' and teachers' overall oral health knowledge scores. Descriptive statistics of frequency distribution, percentages, and mean knowledge scores were calculated for oral health education. The percentage of correct responses to every question between students and teachers was compared using the Chisquare tests. An overall Mean knowledge score was compared between students and teachers using an independent $t$-test. A similar test was applied to compare the mean oral health knowledge score between gender and nationality. While one-way analysis of variance (ANOVA) followed by Tukey's multiple comparison tests was applied to compare the mean knowledge score in different students' grades. The correlation of overall knowledge between students and teachers was performed using Pearson's correlation test. For all statistical purposes, $P<0.05$ was considered statistically significant. All the analyses were performed using SPSS version 25 (IBM, Armonk: New York, USA).

\section{Results}

A total of 1864 subjects from rural area government primary schools [students $(\mathrm{N}=1538)$ and teachers $(\mathrm{N}=326)]$ participated in this study. The majority of the students were females 841 (54.7\%), Saudi nationals 1376 $(89.5 \%)$, and studying in 5th grade $446(29 \%)$. Most of the teacher participants were females, $199(61.0 \%)$ and Saudi nationals 326 (100.0\%). The characteristics of the study participants are shown in (Table 1).

Oral health knowledge categories and distribution of the students and teachers in each category are shown in (Table 2). Of all the students 711, 724 and 103 were in poor, average and high knowledge categories. Oral health knowledge of male versus female students in poor $(64.4 \%$ vs $35.6 \%)$, average $(29.1 \%$ vs $70.9 \%)$ and high $(27.2 \%$ $72.8 \%$ ) categories demonstrated a statistically significant

Table I Characteristics of Study Participants

\begin{tabular}{|l|l|c|c|c|c|}
\hline \multicolumn{2}{|l|}{ Characteristics } & \multicolumn{2}{c|}{$\begin{array}{c}\text { Student } \\
\text { (N=1538) }\end{array}$} & \multicolumn{2}{c|}{$\begin{array}{c}\text { Teacher } \\
\text { (N=326) }\end{array}$} \\
\cline { 3 - 6 } & & $\mathbf{n}$ & $\%$ & $\mathbf{n}$ & $\%$ \\
\hline Gender & Male & 697 & $(45.3 \%)$ & 127 & $(39.0 \%)$ \\
& Female & 841 & $(54.7 \%)$ & 199 & $(61.0 \%)$ \\
\hline Nationality & Saudi & 1376 & $(89.5 \%)$ & 326 & $(100.0 \%)$ \\
& Non- & 162 & $(10.5 \%)$ & 0 & $(0.0 \%)$ \\
& Saudi & & & & \\
\hline Educational level of & 3rd & 335 & 21.8 & - & - \\
Students & 4th & 353 & 23.0 & - & - \\
& 5th & 446 & 29.0 & - & - \\
& 6th & 404 & 26.3 & - & - \\
\hline
\end{tabular}


Table 2 Demographic Variables and Categories of the Oral Health Knowledge

\begin{tabular}{|c|c|c|c|c|c|c|c|c|c|}
\hline \multicolumn{3}{|c|}{ Variables } & \multicolumn{2}{|c|}{ Poor } & \multicolumn{2}{|c|}{ Adequate } & \multicolumn{2}{|c|}{ High } & \multirow[t]{2}{*}{$\mathbf{P} \pi$} \\
\hline & & & $\mathbf{n}$ & $\%$ & $\mathbf{n}$ & $\%$ & $\mathbf{n}$ & $\%$ & \\
\hline \multirow[t]{3}{*}{ Students } & Gender & $\begin{array}{l}\text { Male } \\
\text { Female } \\
\text { Total }\end{array}$ & $\begin{array}{l}458 \\
253 \\
711\end{array}$ & $\begin{array}{c}64.4 \% \\
35.6 \% \\
100.0 \%\end{array}$ & $\begin{array}{l}211 \\
513 \\
724\end{array}$ & $\begin{array}{c}29.1 \% \\
70.9 \% \\
100.0 \%\end{array}$ & $\begin{array}{c}28 \\
75 \\
103\end{array}$ & $\begin{array}{c}27.2 \% \\
72.8 \% \\
100.0 \%\end{array}$ & $<0.001$ \\
\hline & Nationality & $\begin{array}{l}\text { Saudi } \\
\text { Non-Saudi } \\
\text { Total }\end{array}$ & $\begin{array}{c}647 \\
64 \\
711\end{array}$ & $\begin{array}{c}91.0 \% \\
9.0 \% \\
100.0 \%\end{array}$ & $\begin{array}{c}643 \\
81 \\
724\end{array}$ & $\begin{array}{c}88.8 \% \\
11.2 \% \\
100.0 \%\end{array}$ & $\begin{array}{c}86 \\
17 \\
103\end{array}$ & $\begin{array}{l}83.5 \% \\
16.5 \% \\
100.0 \%\end{array}$ & 0.05 \\
\hline & Grade & $\begin{array}{l}3 \text { rd } \\
4 \text { th } \\
5 \text { th } \\
6 \text { th } \\
\text { Total }\end{array}$ & $\begin{array}{l}14 \mid \\
183 \\
207 \\
180 \\
7 \mid 1\end{array}$ & $\begin{array}{c}19.8 \% \\
25.7 \% \\
29.1 \% \\
25.3 \% \\
100.0 \%\end{array}$ & $\begin{array}{l}155 \\
150 \\
211 \\
208 \\
724\end{array}$ & $\begin{array}{c}21.4 \% \\
20.7 \% \\
29.1 \% \\
28.7 \% \\
100.0 \%\end{array}$ & $\begin{array}{c}39 \\
20 \\
28 \\
16 \\
103\end{array}$ & $\begin{array}{c}37.9 \% \\
19.4 \% \\
27.2 \% \\
15.5 \% \\
100.0 \%\end{array}$ & $<0.001$ \\
\hline Teachers & Gender & $\begin{array}{l}\text { Male } \\
\text { Female } \\
\text { Total }\end{array}$ & $\begin{array}{l}16 \\
10 \\
26\end{array}$ & $\begin{array}{c}61.5 \% \\
38.5 \% \\
100.0 \%\end{array}$ & $\begin{array}{c}96 \\
130 \\
226\end{array}$ & $\begin{array}{c}42.5 \% \\
57.5 \% \\
100.0 \%\end{array}$ & $\begin{array}{l}15 \\
59 \\
74\end{array}$ & $\begin{array}{c}20.3 \% \\
79.7 \% \\
100.0 \%\end{array}$ & $<0.001$ \\
\hline
\end{tabular}

Note: "Chi-square test.

difference $(<0.001)$. Similarly, percentage of Saudi vs nonSaudi nationals in poor $(91.0 \%$ vs $9.0 \%)$, average $(88.8 \%$ vs $11.2 \%)$ and high ( $83.5 \%$ vs $16.5 \%)$ oral health knowledge differed significantly $(\mathrm{p}=0.05)$. Percentage of students in 3rd, 4th, 5th and 6th grades differed significantly across poor $(19.8 \%, 25.7 \%, 29.1 \%$ and $25.3 \%)$, average $(21.4 \%, 20.7 \%, 29.1 \%$ and $28.7 \%)$ and high $(37.9 \%, 19.4 \%, 27.2 \%$ and $15.5 \%) \quad(p<0.001)$. Similarly, significant differences between male and female schoolteachers regarding the categories of oral health knowledge were evident.

Comparison of overall mean knowledge scores across different gender, nationality, and grades of the students and between male and female teachers is shown in (Table 3). Female students (10.77 \pm 2.83$)$ showed significantly higher overall mean oral health knowledge scores than males $(8.25 \pm 3.32)(\mathrm{p}<0.001)$. Non-Saudi students (10.22 \pm 3.17$)$ demonstrated significantly higher mean

Table 3 Comparison of Overall Mean Knowledge Score

\begin{tabular}{|c|c|c|c|c|c|c|}
\hline \multicolumn{3}{|c|}{ Variables } & $\mathbf{n}$ & Mean & SD & $\mathbf{p}$ \\
\hline \multirow[t]{3}{*}{ Students } & Gender ${ }^{\pi}$ & $\begin{array}{l}\text { Male } \\
\text { Female }\end{array}$ & $\begin{array}{l}697 \\
841\end{array}$ & $\begin{array}{c}8.25 \\
10.77\end{array}$ & $\begin{array}{l}3.32 \\
2.83\end{array}$ & $<0.001$ \\
\hline & Nationality" & $\begin{array}{l}\text { Saudi } \\
\text { Non-Saudi }\end{array}$ & $\begin{array}{l}1376 \\
162\end{array}$ & $\begin{array}{c}9.56 \\
10.22\end{array}$ & $\begin{array}{l}3.32 \\
3.17\end{array}$ & 0.016 \\
\hline & Grade $^{\S}$ & $\begin{array}{l}3 \text { rd } \\
4 \text { th } \\
5 \text { th } \\
6 \text { th }\end{array}$ & $\begin{array}{l}335 \\
353 \\
446 \\
404\end{array}$ & $\begin{array}{c}10.11 \\
9.04 \\
9.71 \\
9.67\end{array}$ & $\begin{array}{l}3.68^{\mathrm{A}} \\
3.49^{\mathrm{B}} \\
3.12^{\mathrm{A}} \\
2.93^{\mathrm{A}}\end{array}$ & $<0.001$ \\
\hline Teacher & Gender ${ }^{\pi}$ & $\begin{array}{l}\text { Male } \\
\text { Female }\end{array}$ & $\begin{array}{l}127 \\
199\end{array}$ & $\begin{array}{l}11.75 \\
13.17\end{array}$ & $\begin{array}{l}2.26 \\
2.25\end{array}$ & $<0.001$ \\
\hline
\end{tabular}

Notes: ${ }^{T I I n d e p e n d e n t ~} t$-test, ${ }^{\S}$ one-way ANOVA, the superscripts A, B are used to indicate pairwise comparisons. Different superscript letters in a column are significantly different. 
knowledge scores than the Saudi students $(9.56 \pm 3.32)$ $(\mathrm{p}=0.016)$. Fourth-grade students $(9.04 \pm 3.49)$ compared to 3 rd $(10.11 \pm 3.68), 5$ th $(9.71 \pm 3.12)$, and 6th $(9.67 \pm 2.93)$ graders demonstrated significantly lower mean knowledge scores $(p<0.001)$. However, no significant differences were observed in the mean oral health knowledge scores of 3rd, 5th, and 6th-grade students. Similarly, female teachers $(13.17 \pm 2.25)$ demonstrated significantly higher overall oral health knowledge scores compared to male teachers $(11.75 \pm 2.26)(\mathrm{p}<0.001)$.

Oral health knowledge item-specific correct responses between students and teachers are shown in Table 4. A large percentage of teachers compared to the students answered correctly to the items. Why do we need our teeth? [994 (64.6\%) vs 295 (90.5\%)], How many milk teeth do we have?[312 (20.3\%) vs.105 (32.2\%)], How many permanent teeth do we have? [434 (28.2\%) vs.190 (58.3\%)], What is the purpose of tooth brushing? [1240 $(80.6 \%)$ vs $314(96.3 \%)$ ], What should be the interval for the change of toothbrush? [986 (64.1\%) vs $230(70.6 \%)$ ], What does dental plaque mean? [319 (20.7\%) vs 89 (27.3\%)] What can dental plaque cause?[487 (31.7\%) vs 194 (59.5\%)], Are soft drinks affect teeth adversely?[1248
(81.1\%) vs.312 (95.7\%)], What is the effect of sweets retention on dentition? [1200 (78.0\%) vs $278(85.3 \%)$ ], What is the reason for tooth decay? [614 (39.9\%) 248 vs (76.1\%)], What are the methods to prevent dental decay? [1234 (80.2\%) vs $312(95.7 \%)]$, How many layers are in the teeth? [362 (23.5\%) vs.169 (51.8\%)], Does the health of mouth and dentition impact the health of the body? [878 (57.1\%) vs.316 (96.9\%)], Loss of teeth can interfere with speech? [1125 (73.1\%) vs $320(98.2 \%)]$, Is it possible to move irregularly placed teeth into the correct position? [1055 (68.6\%) vs.305 (93.6\%)]. Comparison questionnaire responses for the items (1 and 5-18) between teachers and students showed statistically significant differences $(\mathrm{p}<0.05)$.

On the contrary, students demonstrated higher correct responses to item 2, How many times do you brush every day? [1017 (66.1\%) vs $189(58.0 \%)]$, item 3, When do you brush your teeth? [1000 (65.0\%) vs 195 $(59.8 \%)]$, and item 4, How many sets of dentitions do we have? [309 (20.1\%) vs $54(16.6 \%)]$.

The comparison of the overall mean knowledge score between students and teachers is shown in Figure 1. Teachers (12.62 \pm 2.36$)$ demonstrated significantly higher

Table 4 Item Specific Correct Responses Between Student and Teacher

\begin{tabular}{|c|c|c|c|c|c|c|}
\hline \multirow[t]{2}{*}{ Items } & \multirow[t]{2}{*}{ Questions** } & \multicolumn{2}{|c|}{ Students $(N=1538)$} & \multicolumn{2}{|c|}{ Teachers $(\mathrm{N}=326)$} & \multirow[t]{2}{*}{$\mathbf{P}$} \\
\hline & & $\mathbf{n}$ & $\%$ & $\mathbf{n}$ & $\%$ & \\
\hline 1 & Why do we need our teeth & 994 & $(64.6 \%)$ & 295 & (90.5\%) & $<0.001 *$ \\
\hline 2 & How many times do you brush every day & 1017 & $(66.1 \%)$ & 189 & $(58.0 \%)$ & $0.005^{*}$ \\
\hline 3 & Daily when do you brush your teeth? & 1000 & $(65.0 \%)$ & 195 & $(59.8 \%)$ & 0.075 \\
\hline 4 & How many sets of dentitions do we have? & 309 & $(20.1 \%)$ & 54 & $(16.6 \%)$ & 0.144 \\
\hline 5 & How many milk teeth do we have? & 312 & $(20.3 \%)$ & 105 & (32.2\%) & $<0.001 *$ \\
\hline 6 & How many permanent teeth do we have? & 434 & $(28.2 \%)$ & 190 & $(58.3 \%)$ & $<0.001 *$ \\
\hline 7 & What is the purpose of tooth brushing? & 1240 & (80.6\%) & 314 & (96.3\%) & $<0.001 *$ \\
\hline 8 & What should be the interval for the change of toothbrush? & 986 & $(64.1 \%)$ & 230 & $(70.6 \%)$ & $0.026 *$ \\
\hline 9 & What does dental plaque mean? & 319 & $(20.7 \%)$ & 89 & $(27.3 \%)$ & $0.009 *$ \\
\hline 10 & What can dental plaque cause? & 487 & $(31.7 \%)$ & 194 & $(59.5 \%)$ & $<0.001 *$ \\
\hline II & Are soft drinks affect teeth adversely? & 1248 & $(81.1 \%)$ & 312 & (95.7\%) & $<0.001 *$ \\
\hline 12 & What is the effect of sweets retention on dentition? & 1200 & (78.0\%) & 278 & $(85.3 \%)$ & $0.003^{*}$ \\
\hline 13 & What is the reason for tooth decay? & 614 & $(39.9 \%)$ & 248 & (76.1\%) & $<0.001 *$ \\
\hline 14 & What are the methods to prevent dental decay? & 1234 & (80.2\%) & 312 & (95.7\%) & $<0.001 *$ \\
\hline 15 & How many layers are in the teeth? & 362 & $(23.5 \%)$ & 169 & $(51.8 \%)$ & $<0.001 *$ \\
\hline 16 & Does the health of mouth and dentition impact the health of the body? & 878 & $(57.1 \%)$ & 316 & $(96.9 \%)$ & $<0.001 *$ \\
\hline 17 & Loss of teeth can interfere with speech? & 1125 & (73.1\%) & 320 & (98.2\%) & $<0.001 *$ \\
\hline 18 & Is it possible to move irregularly placed teeth into the correct position? & 1055 & $(68.6 \%)$ & 305 & $(93.6 \%)$ & $<0.001 *$ \\
\hline
\end{tabular}

Notes: *p<0.05. **Adapted with permission from Wolters Kluwer Health, Inc.: Al Saffan AD, Baseer MA, Alshammary AA, Assery M, Kamel A, Rahman G. Impact of Oral Health Education on Oral Health Knowledge of Private School Children in Riyadh City, Saudi Arabia. J Int Soc Prev Community Dent. 2017;7(Suppl 3):SI86-SI93. doi: I0.4I03/ jispcd.JISPCD_372_I7. ${ }^{19}$ Available from: https://www.jispcd.org/article.asp?issn=2231-0762; year=20I7; volume=7;issue=9; spage=186;epage=193;aulast=Al. Copyright: C) 2017 Journal of International Society of Preventive and Community Dentistry. The Creative Commons license does not apply to this content. Use of the material in any format is prohibited without written permission from the publisher, Wolters Kluwer Health, Inc. Please contact permissions@lww.com for further information. 


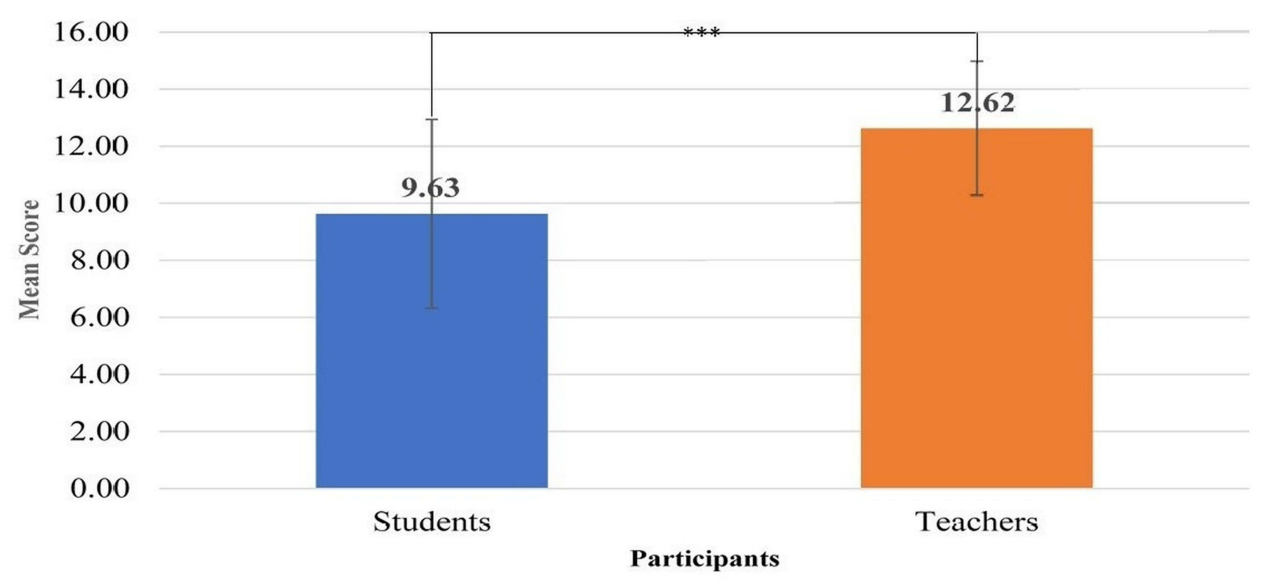

Figure I Comparison of overall mean knowledge score between students and teachers $(* * * p<0.00 \mathrm{I})$.

overall mean knowledge scores compared to the students $(9.63 \pm 2.36)(\mathrm{p}<0.001)$.

\section{Discussion}

Children have the right to good health as well as the right to have an education. School is an institution that structures children's behavior, attitudes, and perspectives on life. Healthy lifestyles instilled in children are carried over into adulthood. Children spend roughly one-third of their daily activities in school. Schools have long been recognized for their role in promoting children's health. The World Health Organization's Global School Health Initiative promotes "health-promoting schools" to create a healthy living, learning, and working environment. This initiative aims to improve students' health, school personnel, families, and other community members. ${ }^{20}$ The role of a teacher becomes extremely valuable and essential as they can influence thousands of students and their parents by providing oral health instructions and preventive dental education. $^{21}$

School teachers were trained and used as health educators in many parts of the world to reduce dental plaque, improve oral hygiene, and provide emergency care during dental trauma to children ${ }^{22,23}$ due to their basic understanding of oral health. ${ }^{24}$ Not only does this preventive strategy save young children from the agony of awful dental treatment, but it also protects them from missing school hours. $^{4}$

In Saudi Arabia, studies have primarily reported on the oral health knowledge of schoolchildren and teachers from urban and large cities where all types of dental care facilities are available. However, little information exists on the oral health knowledge of schoolchildren and teachers from remote and rural areas. As a result, the current study was conducted to assess and compare the oral health knowledge of government primary school children and teachers from rural areas.

In this study, primary students studying in government schools demonstrated an overall average knowledge of oral health. However, study findings showed that primary school students in rural areas exhibited a high level of knowledge in three areas of oral health with correct responses ranging from $80.2 \%$ to $81.1 \%$. Almost more than $80.6 \%$ of students were knowledgeable about the purpose of toothbrushing, which is in line with $81.6 \%$ of private school children in Riyadh, ${ }^{19} 96.3 \%$ in Makkah, ${ }^{25}$ $83 \%$ in India. ${ }^{26}$ Soft drinks containing acids and sugars have both acidogenic and cariogenic properties. Nearly $81.1 \%$ of the students were aware of the soft drink's adverse effect on the teeth. This finding is similar to the previously reported studies in Saudi Arabia. ${ }^{25,27}$ In this study, $80.2 \%$ of students were aware of preventing dental decay by regular brushing with fluoridated toothpaste. On the contrary, only $36.6 \%$ of the students in Abha knew about the role of fluoride in preventing tooth decay. ${ }^{16}$ Another study conducted in the Zulfi region of Saudi Arabia showed that $61 \%$ of children had good knowledge about fluoride and knew that it prevents dental caries. ${ }^{28}$

The students reported an adequate level of knowledge with correct responses ranging between $(57.1 \%$ to $78 \%)$ in regards to the need for the teeth, frequency of toothbrushing every day, daily brushing time, the interval for the change of toothbrush, the effect of sweet retention on dentition, oral health has an impact on the health of the body, Loss of teeth interferes with speech and possibility 
of moving irregularly placed teeth into the correct position.

Similarly, poor knowledge was observed regarding the sets of dentitions, the number of primary and permanent teeth in humans, meaning and causes of dental plaque, reasons for tooth decay, and layers in teeth. It could be due to the concerns of access to health information in rural areas. Since public health services are mainly distributed relative to the population density, ${ }^{29}$ thereby leading to less availability and access to oral health information in rural areas. Furthermore, knowledge deficiencies could be attributed to the socioeconomic variables in rural areas. ${ }^{28}$

In general, rural school teachers demonstrated satisfactory oral health knowledge. More female teachers than male teachers were classified as having adequate or higher oral health knowledge. Moreover, female teachers demonstrated significantly higher oral health knowledge than their male counterparts. This could be due to the higher levels of oral health literacy found among female teachers. This study finding is in line with the various studies reported in Saudi Arabia and other countries. ${ }^{14,21,30-34}$ However, teachers displayed a lower level of oral health knowledge regarding the sets of human dentition, number of milk teeth, and the meaning of dental plaque.

A comparison of oral health knowledge between rural students and teachers indicated significantly higher knowledge among school teachers in all the items except for item 2 (How many times do you brush every day), Item 3 (Daily when do you brush your teeth?), and item 4 (How many sets of dentitions do we have?). This could be because school teachers are likely to overestimate their oral health expertise due to their social position as mentors to their students. ${ }^{35}$ Our finding is correlated with the study reported by Vozza et al. They noted that a school-based program is more effective in content learning for children when knowledge acquisition is followed by applying and verifying theoretical and practical skills in oral health. ${ }^{36}$ In spite of several reported studies, there is currently inadequate data to support the effectiveness of primary schoolbased behavioral therapies for caries prevention. The impact of the various educational intervention on plaque outcomes and children's oral health knowledge acquisition is understudied. ${ }^{37}$

\section{Limitations}

The first limitation of this study is its sample, which was not equally stratified across school students, teachers, and gender of the study participants, but this can be justified because the sample was designed to be representative of the actual demographics of rural areas in Saudi Arabia as possible. The second limitation was that the study only included students from public schools because the government manages the bulk of schools in Saudi Arabia's rural provinces. The third limitation was the selection bias, which was unavoidable in the convenience (non-random) sampling approach in which schools were selected from rural areas of a single region-difficulties in accessing female schools by male investigators due to local norms. Finally, the study focused solely on the knowledge element of oral health, with no emphasis on attitudes or practices.

It is the first study that assessed and compared oral health knowledge of rural students and teachers in Saudi Arabia. It has identified the oral health knowledge gaps within and between rural school students and teachers. This study supports the role of school teachers as oral health educators since they were found to have higher oral health knowledge. The study adds to the body of data supporting the role of school teachers in educating the students about oral health in rural areas of the schools in Saudi Arabia. Oral health promoters should develop a conceptual framework to educate and evaluate the oral health knowledge of rural school students and teachers based on well-defined constructs. Future studies on oral health knowledge of students and teachers from different rural regions of Saudi Arabia are needed to fully understand the oral health knowledge gaps.

\section{Conclusion}

Basic oral health knowledge was adequate among 3-6th grade government primary school students and teachers in rural areas of the Riyadh region. Among students' females, non-Saudi nationals, and 3rd graders showed a higher level of oral health knowledge. Similarly, female teachers demonstrated a higher level of oral health knowledge. Oral health promoters should address the existing oral health knowledge gaps and design a model to continuously evaluate educational oral health programs targeted towards schools in Saudi Arabia. It is recommended that the teachers in Saudi Arabia's rural areas be well-trained to provide oral health education to improve the students' oral health knowledge.

\section{Data Sharing Statement}

The datasets used in this study can be available from the corresponding author upon reasonable request. 


\section{Acknowledgments}

The authors are thankful to the Research center of Riyadh Elm University for providing needed support during the research.

\section{Disclosure}

The authors declare that they have no conflicts of interest in this work.

\section{References}

1. Petersen PE, Bourgeois D, Ogawa H, Estupinan-Day S, Ndiaye C. The global burden of oral diseases and risks to oral health. Bull World Health Organ. 2005;83(9):661-669.

2. Al Agili DE. A systematic review of population-based dental caries studies among children in Saudi Arabia. Saudi Dent J. 2013;25 (1):3-11. doi:10.1016/j.sdentj.2012.10.002

3. Frencken JE, Sharma P, Stenhouse L, Green D, Laverty D, Dietrich T. Global epidemiology of dental caries and severe periodontitis a comprehensive review. J Clin Periodontol. 2017;44(Suppl 18): S94-S105. doi:10.1111/jcpe. 12677

4. Gift HC, Reisine ST, Larach DC. The social impact of dental problems and visits. Am J Public Health. 1992;82(12):1663-1668. doi:10.2105/ajph.82.12.1663

5. Bridges SM, Parthasarathy DS, Au TKF, Wong HM, Yiu CKY, McGrath CP. Development of functional oral health literacy assessment instruments: application of literacy and cognitive theories. J Public Health Dent. 2014;74(2):110-119. doi:10.1111/jphd.12033

6. Sun Y, Li C, Zhao Y, Sun J. Trends and developments in oral health literacy: a scientometric research study (1991-2020). BDJ Open. 2021;7(1):13. doi:10.1038/s41405-021-00066-5

7. Horowitz AM, Kleinman DV. Oral health literacy: the new imperative to better oral health. Dent Clin North Am. 2008;52(2):333-344, vi. doi:10.1016/j.cden.2007.12.001

8. ADA. Health literacy in dentistry strategic action plan 2010-2015; 2009.

9. Baker DW, Wolf MS, Feinglass J, Thompson JA, Gazmararian JA, Huang J. Health literacy and mortality among elderly persons. Arch Intern Med. 2007;167(14):1503-1509. doi:10.1001/ archinte.167.14.1503

10. Gupta T, Sequeira P, Acharya S. Oral health knowledge, attitude and practices of a 15-year-old adolescent population in Southern India and their social determinants. Oral Health Prev Dent. 2012;10 (4):345-354.

11. Haque SE, Rahman M, Itsuko K, et al. effect of a school-based oral health education in preventing untreated dental caries and increasing knowledge, attitude, and practices among adolescents in Bangladesh. BMC Oral Health. 2016;16(1):44. doi:10.1186/s12903-016-0202-3

12. Carneiro L, Kabulwa M, Makyao M, Mrosso G, Choum R. Oral health knowledge and practices of secondary school students, tanga, Tanzania. Int J Dent. 2011;2011:806258. doi:10.1155/2011/806258

13. Ryan P. Integrated theory of health behavior change: background and intervention development. Clin Nurse Spec. 2009;23(3):161-170;quiz 171-172. doi:10.1097/NUR.0b013e3181a42373

14. Wyne AH, Al-Ghorabi BM, Al-Asiri YA, Khan NB. Caries prevalence in Saudi primary schoolchildren of Riyadh and their teachers' oral health knowledge, attitude and practices. Saudi Med J. 2002;23 (1):77-81.

15. Kotha SB, Alabdulaali RA, Dahy WT, Alkhaibari YR, Albaraki ASM, Alghanim AF. The influence of oral health knowledge on parental practices among the Saudi Parents of children aged 2-6 years in Riyadh City, Saudi Arabia. J Int Soc Prev Commun Dent. 2018;8(6):565-571. doi:10.4103/jispcd.JISPCD_341_18
16. Al-Qahtani SM, Razak PA, Khan SD. Knowledge and practice of preventive measures for oral health care among male intermediate schoolchildren in Abha, Saudi Arabia. Int J Environ Res Public Health. 2020;17(3):E703. doi:10.3390/ijerph17030703

17. Gowdar IM, Aldamigh SA, Wabran MS, Althwaini AS, Alothman TA, Alnafisah AM. Knowledge and attitude of male schoolteachers towards primary dental care. J Fam Med Prim Care. 2020;9(3):1594-1598. doi:10.4103/jfmpc.jfmpc_1100_19

18. Alshloul MN. Oral health knowledge, attitude, and practice among school children in Abha-Saudi Arabia. $J$ Sch Nurs. 2021;10598405211012980. doi:10.1177/10598405211012981

19. Al Saffan AD, Baseer MA, Alshammary AA, Assery M, Kamel A, Rahman G. Impact of oral health education on oral health knowledge of private school children in Riyadh City, Saudi Arabia. J Int Soc Prev Commun Dent. 2017;7(Suppl 3):S186-S193. doi:10.4103/ jispcd.JISPCD_372_17

20. World Health Organization. Promoting health through schools: report of a WHO expert committee on comprehensive school health education and promotion. World Health Organization; 1997. Available from: https://apps.who.int/iris/handle/10665/41987. Accessed August 8, 2021.

21. Aljanakh M, Siddiqui AA, Mirza AJ. Teachers' knowledge about oral health and their interest in oral health education in Hail, Saudi Arabia. Int J Health Sci. 2016;10(1):87-93.

22. Petersen PE, Kwan S. Evaluation of community-based oral health promotion and oral disease prevention-WHO recommendations for improved evidence in public health practice. Community Dent Health. 2004;21(4 Suppl):319-329.

23. Niviethitha S, Bhawarlal C, Ramkumar H, Dhakshanamoorthy S, Shanmugam H. Effectiveness of an audio-visual aid on the knowledge of school teachers regarding the emergency management of dental injuries. Dent Traumatol. 2018;34(4):290-296. doi:10.1111/ edt. 12405

24. Ramroop V, Wright D, Naidu R. Dental health knowledge and attitudes of primary school teachers toward developing dental health education. West Indian Med J. 2011;60(5):576-580.

25. Bafaraja NM, Bafaraja MA, Alzaidi D, et al. Assessment of oral hygiene knowledge, attitude and practice among children in Makkah City, Saudi Arabia: a cross-sectional study. J Umm Al-Qura Univ Med Sci. 2020;6(1):1-3.

26. Mehta A, Kaur G. Oral health-related knowledge, attitude, and practices among 12-year-old schoolchildren studying in rural areas of Panchkula, India. Indian J Dent Res. 2012;23(2):293. doi:10.4103/ 0970-9290.100446

27. Rafi AT, Syed MY, Zakirulla M, Naseem VS, Alzamzami M. Oral hygiene knowledge and practices among school children in a rural area of southern Saudi Arabia. Int J Contemp Dent. 2012;3:57-62.

28. Kannan SP, Alfahaid SF, Alharbi AS, et al. Oral hygiene behavior of school children in Saudi Arabia: a descriptive cross-sectional survey. Int J Clin Pediatr Dent. 2020;13(1):66-71. doi:10.5005/jp-journals $-10005-1710$

29. Baazeem M, Tennant M, Kruger E. Determining variations in access to public hospitals in Makkah, Kingdom of Saudi Arabia: a GIS-based approach. Saudi J Health Syst Res. 2021;1(1):26-32. doi:10.1159/000513632

30. Almas K, Al-Malik TM, Al-Shehri MA, Skaug N. The knowledge and practices of oral hygiene methods and attendance pattern among school teachers in Riyadh, Saudi Arabia. Saudi Med J. 2003;24 (10):1087-1091.

31. Ahmad MS. Oral Health knowledge and attitude among primary school teachers of Madinah, Saudi Arabia. J Contemp Dent Pract. 2015;16(4):275-279. doi:10.5005/jp-journals-10024-1675

32. Tikare S, AlQahtani NA. Oral health knowledge and attitudes of primary school teachers toward school-based oral health programs in Abha-Khamis, Saudi Arabia. Saudi J Oral Sci. 2017;4(2):72. doi:10.4103/sjos.SJOralSci_18_17 
33. Mwangosi IEAT, Nyandindi U. Oral health related knowledge, behaviours, attitude and self-assessed status of primary school teachers in Tanzania. Int Dent J. 2002;52(3):130-136. doi:10.1111/j.1875595x.2002.tb00617.x

34. Kumar S, Kulkrani S, Jain S, et al. Oral health knowledge, attitudes and behavior of elementary school teachers in India. Rev Gaúcha Odontol. 2012;60(1):19-25.

35. Yilmaz G, Riad A, Krsek M, Kurt H, Attia S. Oral health-related knowledge, attitudes and behaviours of elementary school teachers Int J Environ Res Public Health. 2021;18(11):6028. doi:10.3390/ ijerph 18116028
36. Vozza I, Capasso F, Calcagnile F, et al. School-age dental screening: oral health and eating habits. Clin Ter. 2019;170(1):e36-e40. doi:10.7417/CT.2019.2105

37. Cooper AM, O’Malley LA, Elison SN, et al. Primary school-based behavioural interventions for preventing caries. Cochrane Database Syst Rev. 2013;(5):CD009378. doi:10.1002/14651858.CD009378. pub2

\section{Publish your work in this journal}

Clinical, Cosmetic and Investigational Dentistry is an international, peer-reviewed, open access, online journal focusing on the latest clinical and experimental research in dentistry with specific emphasis on cosmetic interventions. Innovative developments in denta materials, techniques and devices that improve outcomes and patient satisfaction and preference will be highlighted. The manuscript management system is completely online and includes a very quick and fair peer-review system, which is all easy to use. Visit http://www.dovepress.com/testimonials.php to read real quotes from published authors. 